\title{
Educating for Peace: A Case Study of a Constructivist Approach to Understanding Peace through Artistic Expression
}

\author{
Young Imm Kang Song \\ Creative Arts in Learning Division, Graduate School of Education, Lesley University, Massachusetts, USA \\ Email: ysong@lesley.edu
}

Received November $9^{\text {th }}$, 2011; revised December 20 $0^{\text {th }}$, 2011; accepted December $30^{\text {th }}, 2011$

\begin{abstract}
This paper discusses a project called "Making a PEACE of Paper", which illustrates how children can explore the meaning and idea of peace through art while, at the same time, understanding other cultures in a meaningful and respectful way. It describes how students can use art and technology to overcome spatial boundaries and exchange creative ideas with students in another country. It also considers how to create "shared spaces" that may help students from different backgrounds to better understand each other's cultures. The visual art and technology projects, methods, and pedagogy discussed in this paper can be replicated by teachers and community peace educators easily and with minimal (if any) costs. Through this project, teachers and community peace educators may explore what "a peaceful future" means to students and how they think this may be attained. This project provides an engaging framework for students to share ideas, discover meaning, and advance their own understanding of peace through collaboration, dialogue, and creation of artworks that represent their ideas. It is flexible and adaptable to various contexts, age groups, and settings. It also provides a model for authentic student voice in learning, extensive higher-level thinking, and a platform for collectively reaching new insights. The goal of this project is to provide a compelling way to allow students to "see" peace in a transformed way that will help lead to a more peaceful society. It is hoped that this project will motivate teachers and community educators to create a new vision of teaching this topic of peace.
\end{abstract}

Keywords: Peace Project; Art Education; Handmade Paper; Paper-Mâché Globe; Visual Art and Technology Project; Cultural Studies; Peace Education; Peace-Building Activity; Paper-Making Process

\section{Introduction}

In the age of terrorism and numerous violent conflicts all over the world, the importance of educating children about the values of peace and cooperation has taken on newfound importance.

According to UNESCO, "The engagement of creativity from an early age is one of the best guarantees of growth in a healthy environment of self-esteem and mutual respect-critical ingredients for building a culture of peace" (One World Classrooms, 2011). Mahatma Gandhi also stressed the importance of educating youth about peace at an early age: "If we are to teach real peace in this world, and if we are to carry on a real war against war, we shall have to begin with the children" (Dayton Peace Museum, 2011).

As such, it is important to develop a more modern view of pedagogy and practice that can help children conceptualize an understanding and a value system for peace in an educational setting. The school setting provides an ideal space for exploring ideas of peace through critical analysis, reflection, dialogue, and collaborative learning. It is a safe space where students can experience new ideas and develop insights and understandings of complex values like peace. Greene (2001) describes education as "an initiation into new ways of seeing, hearing, feeling, moving. It signifies the nurture of a special kind of reflectiveness and expressiveness, a reaching out for meanings, a learning to learn” (p. 7). This makes education uniquely suited for addres-

${ }^{1}$ The phrase "Making a PEACE of Paper" was coined by Professor Nathan Felde at the Art Institute of Boston at Lesley University. sing this complex but important topic that is essential for $21^{\text {st }}$ century learners and citizens.

In this context, what kinds of projects would help students have a meaningful discussion about "peace and its possibilities" and explore these concepts in ways that they had not considered before? It is appropriate to conduct such projects using art because art is a medium that has survived through history and is able to express and communicate people's experiences in a common way. Furthermore, the arts have "sometimes nurtured peace and [at] other times fostered violence. Art is a tool that can communicate and transform the way people think and act. Arts can change the dynamics in intractable interpersonal, inter-communal, national, and global conflicts” (Shank \& Schirich, 2008, p. 218). Art also has an important universal quality that transcends race, nationality, religion and other barriers that often deter communication and understanding. Ishaq (2004) notes that art is independent and can help build friendship and communication among youth around the world while providing an excellent medium for international cooperation and understanding (p. 41).

This paper will discuss an example of a project called "Making a PEACE of Paper" ${ }^{1}$ that shows how children can explore the meaning and idea of peace through art while, at the same time, understanding other cultures in a meaningful and respectful way. It describes how students can use art and technology to overcome spatial boundaries and exchange creative ideas with students in another country. It also considers how to create 'shared spaces' that may help students from different backgrounds to better understand each other's cultures. The visual art and tech- 
nology projects, methods, and pedagogy discussed in this paper can be replicated by teachers and community peace educators easily and with minimal (if any) costs.

\section{Process}

This section will describe how teacher Kim KyungSu's sixth grade class at Daeja Elementary School in Gwangju, South Korea came to understand the concept of peace, crafted a vision for peace, and expressed a shared hope for peace through the "Making a PEACE of Paper” project. It is important to note that this project utilized a constructivist approach in which one activity led into the next and was directly influenced by the ideas and reactions of students. In replication, the ideas might lead the project in a slightly different direction but would ultimately help students reach important insights and understandings of peace. The classroom project at Daeja Elementary consisted of five steps. Each is discussed in turn below.

\section{Writing a Found Poem}

The definition of a found poem is "the poetic equivalent of a collage in visual art. A found poem takes text from non-poem sources and uses it to create a poem" (Clairenstein, 2011). Students first took 15 minutes to walk around school grounds. During this time, they used notepads to write words that they encountered that they liked, disliked, or for some reason piqued their interest. At this point, students were not aware of why they were "collecting" these words and did not know about the project to follow.

After the students returned to the classroom, they were instructed to write a poem on the topic of peace by using only the words that they had collected on their search and some prepositions. Students found this process to be challenging at first due to the requirement of only using words that they had found, but were soon able to use their imagination and creativity to compose a poem. This first opening activity invited students to think about the word "peace" and to be creative in how they could conceptualize it from a variety of source words.

\section{Thinking about, Discussing, and Pantomiming Peace}

To gain a better understanding of how the sixth grade students thought about the idea of peace, the instructor then led a discussion on the following topics: "How do you think about peace?" and "What does peace look like to you?" During this discussion, students overwhelmingly focused on national and international issues, such as the unification of the Korean peninsula and world peace. It was intriguing that only these larger issues that were less directly palpable were discussed, rather than issues of peace in the classroom, between friends, and amongst neighbors. Based on this discussion, it was determined that the appropriate role of an educator would be to help students comprehend that national and international peace stems from the coming together of peaceful relationships that are much more palpable and occur at a local level. In accordance, the instructor engaged the students in a variety of activities that encouraged them to further think about the concept of peace.

One such activity had students convey their understanding of peace through pantomime. Students presented their interpretations to the class by acting out their abstract ideas in a way that was comprehensible to others without utilizing words. Students worked hard to convey their ideas in as concrete of a way as possible, through body motions, facial expressions, and other non-verbal cues. Through this process, it seemed that the students were constantly reexamining their conceptualizations and understandings of peace. After the pantomime activity, students engaged in another discussion about what might cause peace to be broken. One of the students' main concerns was that violence and wars would occur as groups and nations fight over a dwindling supply of natural resources.

\section{Creating Handmade Paper}

To extend the idea of trying to mend and foster peace through environmental protection, we decided to use junk mail to make handmade paper that would be used for the subsequent activeties. Students were excited that they could make the art materials for the activities on their own. They were also pleased by the fact that they did not need to ask their parents to buy art materials for the activities. For a week, they created a lot of handmade paper with enthusiasm.

Following is how to make homemade paper using junk mail.

- Rip the junk mail envelope into small bits.

- Then, place the pieces of paper into the blender.

- Add about 2 cups of water.

- Run the blender slowly at first, and then increase the speed. It's up to you how much you should increase the speed. Depending on it, it'll be smooth or rough.

- Then, fill the papermaking tool.

- When it stops dripping, take out the top part of the papermaking tool.

- $\quad$ Place the screen on this top part of the tool.

- Flip it upside down.

- Take out the tool.

- Add one more screen.

- Dry the paper using a towel.

- Take out the top screen.

- If desired, add pressed leaves and some decorative items.

- Air-dry the paper.

After creating the handmade paper, students deliberated about what could be made with these sheets of paper and simultaneously convey the topic of peace. After this brainstorm, students agreed on two projects: first to create several paper-mâché globes, and then to construct a three-dimensional model of a peaceful town.

\section{Creating a Paper-Mâché Globe with an Abstract Portrayal of the Earth}

The students decided to create paper-mâché globes with abstract portrayals of the earth to visually capture the earlier discussion that expressed a concern that environmental destruction could threaten peace. To create the physical structure that would provide a frame, students used paper-mâché techniques. For the spherical shape, they built up several layers by gluing old newspaper around old beach balls. After it dried, students removed the beach ball and were left with a paper-mâché globe that retained the spherical shape. Students then completed the papermâché globe by adding a layer of handmade paper from the previous activity.

For the next part of this project, students worked in teams of two to do an abstract watercolor painting on each of the papermâché globes. Each team agreed on a specific theme on the topic of peace. The final list of themes included, a beautiful earth, 
a suffering earth, a destroyed earth, a hopeful earth, and a peaceful earth. To help students express more creativity, they were encouraged to do abstract portrayals rather than realistic reflections. After some time to deliberate, students drew abstract paintings on the paper-mâché globe using watercolors and their imagination. This creative expression allowed students to envision different possible scenarios in a low-stakes context. John Dewey (1910) suggested the value of this type of process noting, "Imagination also enables us to try things out-again in the mind's eye-without the consequences we might encounter if we had to act upon them empirically. It provides a safety net for experiment and rehearsal (as cited in Eisner, 2002: p. 5).

The following is a selection of quotes from the teams' deliberations while drawing on the globe.

"Let's show how islands will start to disappear as sea levels keep rising more and more. Jeju Island and Tsushima Island will probably disappear. Oh, but maybe there will be some volcanic eruption that makes a new island, too.” (team theme: a suffering earth; team members: SeungYeon \& SeungJun).

"Like in the movie Tomorrow, when global warming gets really bad, we'll probably have a 'little ice age' where the earth will gradually start to freeze. Let's try to convey a 'little ice age'." (team theme: a destroyed earth; team members: SuSeung \& MinSuong) (see Figure 1).

"Let's use blue color to show how people are living together peacefully. How about tan color to express being considerate? And maybe purple color for showing happiness and joy?” (team them: a peaceful earth; team members: SuA \& YeRim) (see Figure 2).

Through this creation, these young students were "perceiving, imagining, searching for meaning” (Greene, 2001: p.35). Their comments during the project demonstrate their analytical thinking of creatively turning ideas into visual expression. SuSeung from the "destroyed earth" team said, "We drew an earth that's angry because the environment is being destroyed. The red island in the middle is a 'trash island,' and we thought of it as the earth's tears of blood” (see Figure 3).

"Do you want to draw about how we can show the earth that we're cheering for it? Yea, let's paint a picture of cheering it on.” (team theme: a hopeful earth; team members: MinJoo \& HeeyYeon).

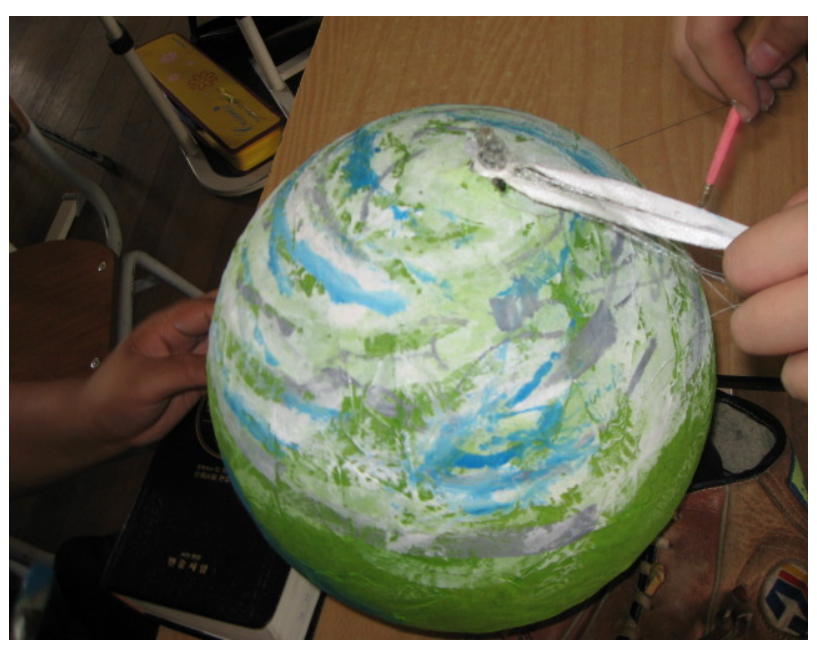

Figure 1.

A destroyed earth, by SuSeung and MinSuong.

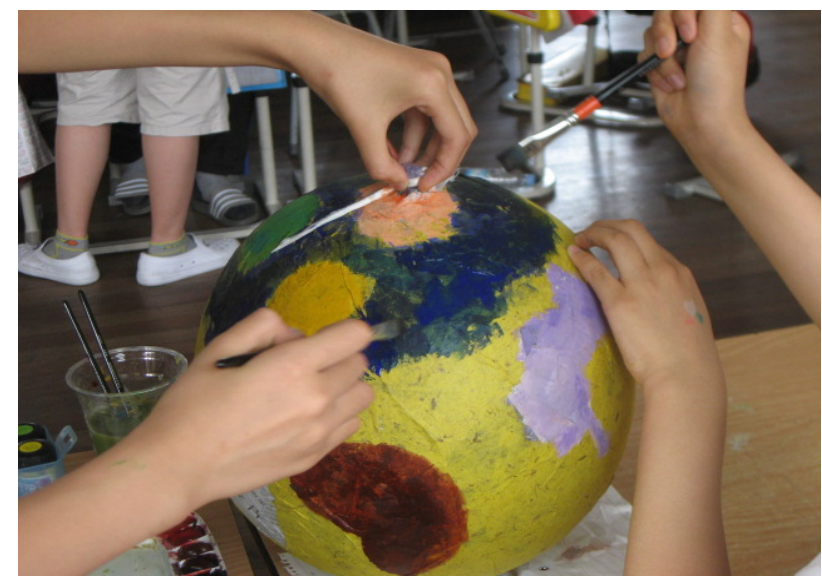

Figure 2.

A peaceful earth, by SuA and YeRim.

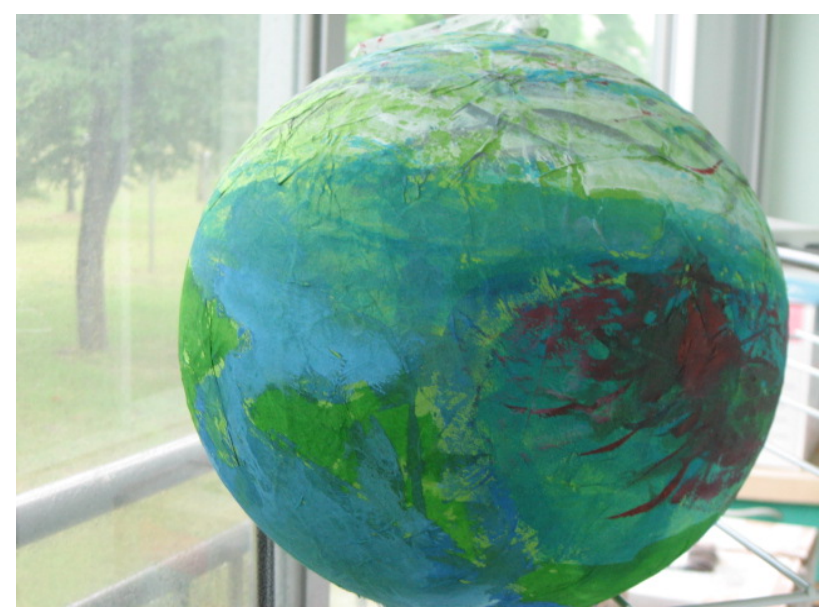

Figure 3.

Trash island, as the earth's tears of blood, by SuSeung and MinSuong.

"Since the earth's owner is nature and not humans, let's fill it up with flowers and trees. It'll be like blowing life into the paper globe." (team theme: a beautiful earth; team members: NaHyun \& SeaJin) (see Figure 4).

MinJoo from the 'hopeful earth' team shared the following: "In the world, there's light and darkness. We believe that when there's destruction, there's also renewal, and when there's despair, there's also hope. If people destroyed the earth, then they should also work to revive it. We believe that if there are arguments, there should also be reconciliations. In our painting, we tried to convey a prayer for Korean reunification as a reconciliatory gesture" (see Figure 5).

This creative representation of peace and hope is made possible by allowing students to use art to unleash imagination. Greene (2001) describes this process of using imagination as a "Mode of grasping, of reaching out that allows what is perceived to be transformed" (p. 31).

The paintings reflected the students' discussions about threats to peace, which included environmental pollution and social uprisings. In a meaningful way, these presentations provided an opportunity for students to view and think about each other's artworks, and to explore each other's perceptions. Although it was clear that peace was still an intangible notion that was hard to express in a concrete manner, the presentations conveyed a 


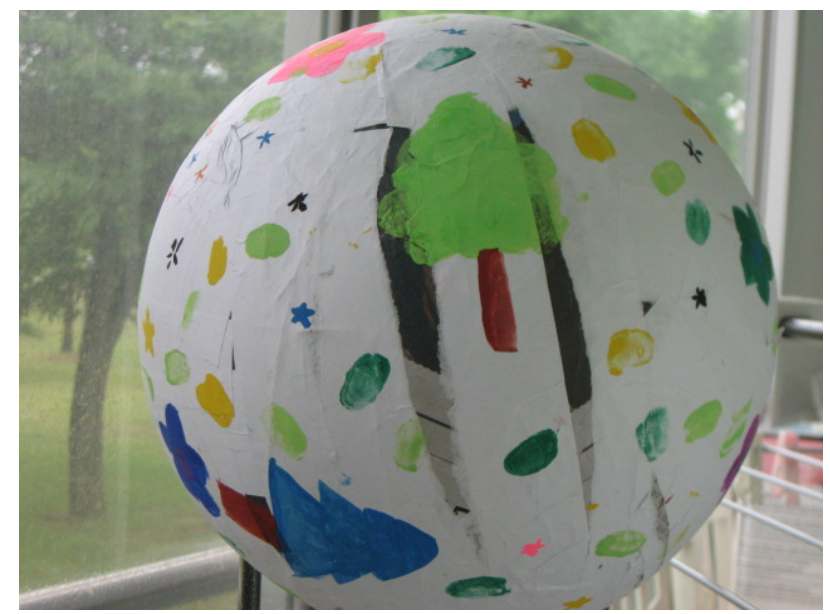

Figure 4.

A beautiful earth, by NaHyun and SeaJin.

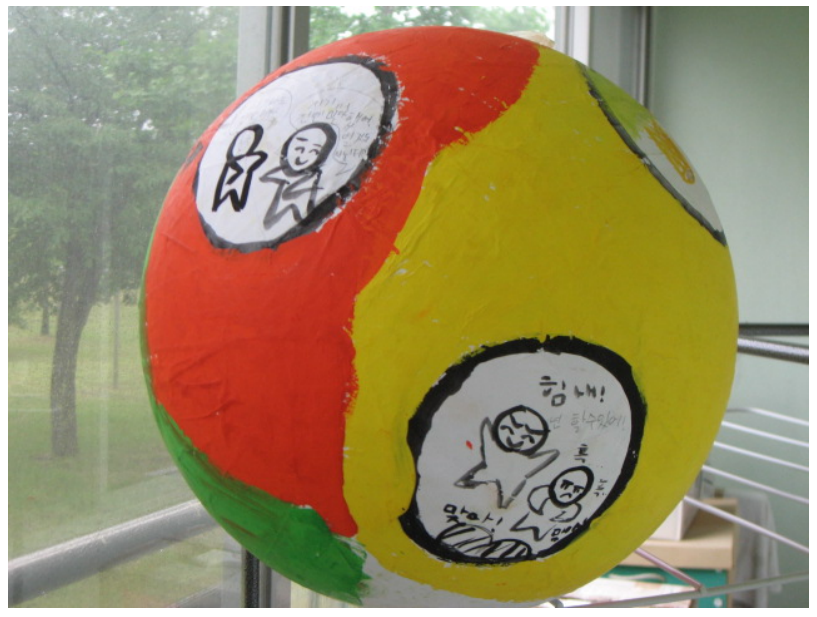

Figure 5.

A hopeful earth, by MinJoo and HeeyYeon.

spirit of passion and the excitement of learning about peace. They also provided students with a forum to unite their concerns about environmental issues with their hopes and ideas for peace in a novel way.

\section{Making a Peaceful Place}

As a final activity, students used the handmade paper from earlier to create a three-dimensional model of a peaceful town. They constructed farms, villages, skyscrapers, green shops, and paved roads with handmade paper tiles. As I observed the students over the course of the project, I noticed how their initial thoughts and conceptualizations about peace gradually transformed into more complex and sophisticated ideas as they used various methods of artistic expression and worked individually, in pairs, and as a whole group to advance their thinking. This evolution of ideas through dialogue and collaboration is a key goal of student learning. Eisner (2002) suggests that "The ultimate aim of education is to enable individuals to become the architects of their own education and through that process to continually reinvent themselves” (p. 240). Teacher Kim KyungSu agreed and said, "I think this project was helpful for students to develop more thoughtful ideas about peace. These kinds of expe- riences will help them develop into successful individuals who actually can accomplish a lot more than they might think.” It was clear from the activity that students had greatly expanded their understanding of what peace means and had thoughtfully considered and conveyed this analysis to their peers through their work. However, beyond the actual products of their work, students had also learned greatly from each other and had the opportunity to hear others views, be exposed to different points of view, and experience different lenses for viewing a familiar concept.

This connection to each other through shared ideas and the advancement of students' own thinking is an important additional outcome for this project. Eisner (2002) notes the value of such this type of growth through the arts. "Education is the process of learning to create ourselves and it is what the arts, both as a process and as the fruits of that process, promote. Work in the arts is not only a way of creating performances and products; it is a way of creating our lives by expanding our consciousness, shaping our dispositions, satisfying our quest for meaning, establishing contact with others, and sharing culture” (p. 3).

\section{Discussion}

This series of activities was unique and challenging in that the instructor did not pre-plan the entire agenda and sequence of activities ahead of time. Instead, the instructor acted as a facilitator and helped formulate project ideas that were based on the direction taken by the students' discussions. For example, after the papermaking activity, it was the students themselves who really determined the nature of the project through which to convey the topic of peace. This type of an open process fosters a sense of leadership and ownership amongst the students, which may arguably result in a heightened degree of motivation and engagement in the activity. It also allows students to be active agents in their own learning process and view themselves as important contributors rather than simply vessels to be filled with external knowledge.

After the conclusion of the project, students reflected on the project and how it had impacted their thinking. "I used to think that world peace could only be achieved by governments. I didn't feel like there was anything I could do, personally. But now I realize that world peace comes from peace in my neighborhood, and in my town” (SeungJun). "I think I've changed a little. I'm more interested in the problems of different countries in the world. I'm reading the news more, and am particularly interested in the World section of newspapers" (SoYeon). "I didn't think that environmental problems had anything to do with peace, but now I realize that they're related, and that I can do something about it" (SeaJin). "If someone sees the art projects that we created, I think they'll realize how beautiful and important peace really is” (JiMin).

Through a variety of artistic activities, students were able to express issues in a more creative way. Using their own self-directed process and series of artistic projects, students unearthed new connections and ideas that excited and inspired them. Greene (2001) similarly notes, "To engage with works of art is to go in search of fresh connections, unsuspected meanings, to engage in acts of continuing discovery” (p. 42). Particularly when they were engaged in a group project, students were also able to experience the social bonds that are integral to being a part of a group, community, and world.

This project not only advanced students' thinking and understanding, but also helped foster a sense of purpose and agency 
around building peace and how they could contribute. Students no longer conceptualized peace as a highly external concept with no immediate relation to their lives, but rather had a sense of how they could help advance peace in more direct ways. This shift in thinking also led to small, but demonstrable shifts in behavior that are likely to endure with their shifted peace paradigm. Ishaq (2006) describes the importance of this change and notes, "For a global culture of peace to be built, the next generation must be imbued with new systems of thinking and feeling. Such approaches are the domain of cognitive science, translated through practice into perceptual and behavioral change" (p. s26).

After the completion of all activities, the projects were uploaded to a password-protected online blog. On this blog, students of similar ages from other countries also shared their "peace projects". This became a place where students could learn about what the local paper materials of other countries were and what other cultures were like. Students were able to further engage with the meaning and definitions of peace by viewing projects from other students who approached this with different backgrounds, values, and experiences. Ultimately, a similar platform could be used for students of different backgrounds and in different countries to learn about a variety of issues that may affect one another in different ways.

This project debuted in June 2011 at Daeja Elementary School in Gwangju, South Korea and at the Maranyundo Girls' School in Nyamata, Rwanda. The project in Korea was guided by Professor Young Imm Kang Song (author) of the Graduate School of Education at Lesley University, and the project in Rwanda was guided by Professor Nathan Felde of the Art Institute of Boston at Lesley University. Although both projects involved handmade papermaking as a common thread, the rest of the activities were designed to fit the particular interests and needs of each of the schools and countries. Since then, this "Making a PEACE of Paper" project has begun to develop into a larger project in which sixth- and seventh-grade students from different countries participate in creating handmade paper as a medium of discussing the topic of peace. In addition to the "shared space" that is created through the website, a physical exchange of the sheets of handmade paper was conducted between the Daeja Elementary School and Maranyundo Girls' School. Such physiccal exchanges are planned with other countries as well in order to create hope for the world by creating a "PEACE of paper".

\section{Conclusion}

By adopting this project, teachers and community peace educators might explore what a peaceful future means to students and how this may be attained. It is hoped that this project will motivate teachers and community educators to create a new vision of teaching this topic. This project provides an engaging framework for students to share ideas, discover meaning, and advance their own understanding of peace through collaboration, dialogue, and creation of art works that represent their ideas. It is flexible and adaptable to various contexts, age groups, and settings but provides a model for authentic student voice in learning, extensive higher-level thinking, and a platform for collectively reaching new insights. Greene (2001) describes the exciting new perspective that can be gained through such work with others, "Being others, offering us new vantage points, it has made us hear as never before; it has enabled us to see” (p. 35). The goal of this project is to provide a compelling way to allow students to "see" peace in a transformed way that will ultimately help lead us to a more peaceful society.

\section{Acknowledgements}

The author would like to thank the sixth graders of classroom 6-1 of Daeja Elementary School in Gwangju, South Korea, and their classroom teacher Kim KyungSu for their participation in this project and for their enthusiasm and passion that inspired this paper. The author also thanks the many people all over the world who have supported this project in various ways.

\section{REFERENCES}

Barron, F., Montuori, A., \& Barron, A. (Eds.) (1997). Creators on creating: Awakening and cultivating the imaginative mind. New York: Tarcher Penguin.

Clairenstein, G. (2011). How to write a “found poem”. URL (last checked 1 September 2011). http://www.ehow.com/how_2173270_write-found-poem.html

Dayton Peace Museum. (2011). Quote. URL (last checked 5 August 2011). http://www.daytonpeacemuseum.org/focus_on_peace.htm

Dewey, J. (1910). How we think. Boston: D.C. Heath. doi:10.1037/10903-000

Eisner, E. W. (2002). The arts and the creation of mind. New Haven: Yale University Press.

Greene, M. (2001). Variations on a blue guitar. New York: Teachers College, Columbia University.

Ishaq, A. (2006). Development of children's creativity to foster peace. Media and Creativity, 368, s26-s27.

Lambourne, W. (2004). Post-conflict peacebuilding: Meeting human needs for justice and reconciliation. Peace, Conflict and Development, 4, 1-24.

McFee, J. K. (1966). Society, art and education. In E. Mattil (Ed.), A seminar in art education for research and curriculum development (pp. 122-140). University Park, PA: Pennsylvania State University.

One World Classrooms (2011). Quote. URL (last checked 19 September 2011). http://www.ccph.com/quotes.html 